4 Janda S, Park K, Fitzgerald JM, et al. Statins in COPD: a systemic review. Chest 2009; 136: 734-743.

5 Anthonisen NR, Skeans MA, Wise RA, et al. The effects of a smoking cessation intervention on 14.5- year mortality: a randomised clinical trial. Ann Intern Med 2005; 142: 233-239.

6 Young RP, Hopkins RJ, Christmas T, et al. COPD prevalence is increased in lung cancer independent of age, sex, and smoking history. Eur Respir J 2009; 34: 380-386.

7 Dasari V, Gallup M, Lemjabbar H, et al. Epithelial-mesenchymal transition in lung cancer: is tobacco the "smoking gun"? Am J Respir Cell Mol Biol 2006; 35: 3-9.

8 Shintani Y, Maeda M, Chaika N, et al. Collagen 1 promotes epithelial-to-mesenchymal transition in lung cancer cells via transforming growth factor- $\beta$ signalling. Am J Respir Cell Mol Biol 2008; 38: 95-104.

9 Yende S, Waterer GW, Tolley EA, et al. Inflammatory markers are associated with ventilatory limitation and muscle dysfunction in obstructive lung disease in well functioning elderly subjects. Thorax 2006; 61: 10-16.

10 Lee TM, Lin MS, Chang NC. Usefulness of C-reactive protein and interleukin-6 as predictors of outcomes in chronic obstructive pulmonary disease receiving pravastatin. Am J Cardiol 2008; 101: 530-535.

DOI: 10.1183/09031936.00117209

\section{From the authors:}

We thank R. Young and co-workers for their constructive comments on our review [1] and we fully agree with them on the potential benefits of statins in chronic obstructive pulmonary disease (COPD) patients. The new information they provide about the potential for statins in reducing lung cancer is particularly important, as this is one of the most common causes of death amongst COPD patients, particularly in those with severe disease. The potential anti-inflammatory effects of statins highlighted in our review might account for the reduction in cancer, although it is possible that statins have additional effects on the signalling pathways which lead to epithelial cancers [1]. For example, lovastatin inhibits the growth of lung cancer cell lines in vitro, in part, by increasing activity of the tumour suppressor protein p53 and the cell-cycle check-point inhibitors p $21^{\mathrm{WAF}}$ and $\mathrm{p} 27^{\mathrm{KIP}}$ [2]. Although the pleiotropic effects of statins provide a convincing scientific rationale for their potential benefit in COPD patients, a note of caution should be applied as the evidence for the benefits of statins is derived solely from observational studies that may have a selection bias. For example, patients with a better prognosis or who receive more intense medical attention may be more likely to be selected for statin therapy. What is needed now is a large, long-term, randomised placebo-controlled study investigating the addition of statins to usual therapy across a range of COPD disease severity; measuring disease progression, exacerbations, comorbidities and all-cause mortality. However, the high costs of such a study and the availability of generic statins mean that such a trial may be difficult to fund. In the meantime, further research investigating the molecular mechanisms of action of statins may be useful in identifying novel targets for the development of new treatments for COPD and its comorbidities [3]. It should also be remembered that there are differences between statins in the range of pleiotropic effects, thus it may not be appropriate to analyse all statins together.

\section{P.J. Barnes* and B.R. Celli ${ }^{\#}$}

*National Heart and Lung Institute, Imperial College London, London, UK, and "Harvard Medical School, Boston, MA, USA.

Correspondence: P.J. Barnes, National Heart and Lung Institute, Imperial College London, London, SW3 6LY, UK. E-mail: p.j.barnes@imperial.ac.uk

Statement of Interest: A statement of interest for P.J. Barnes can be found at www.erj.ersjournals.com/misc.statements.dtl

\section{REFERENCES}

1 Barnes PJ, Celli BR. Systemic manifestations and comorbidities of COPD. Eur Respir J 2009; 33: 1165-1185.

2 Maksimova E, Yie TA, Rom WN. In vitro mechanisms of lovastatin on lung cancer cell lines as a potential chemopreventive agent. Lung 2008; 186: 45-54.

3 Barnes PJ.: Future treatments for COPD and its comorbidities.:: Proc Am Thorac Soc 2008; 857-864.

DOI: 10.1183/09031936.00125909

\title{
Penetrating missile pulmonary embolisation
}

\section{To the Editors:}

We read with interest the review by JoRENS et al. [1] highlighting the causes, diagnosis and treatment of nonthrombotic pulmonary embolism. Certainly, particulate material embolisation, especially from an iatrogenic source, is becoming more common. In fact, another well recognised source of embolisation of cyanoacrylate glue and lipiodol is following endoscopic injection of gastric or oesophageal varices [2, 3].
Embolisation of foreign material related to military trauma or weapons ammunition has become more topical with the presence of worldwide military conflicts in recent years [4]. The management of these patients can be very challenging given the presence of multiple injuries and contaminated wounds. Following adequate resuscitation, total body computed tomography (CT) imaging is often advocated to guide and prioritise treatment for the most life-threatening condition.

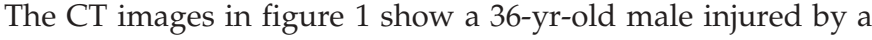



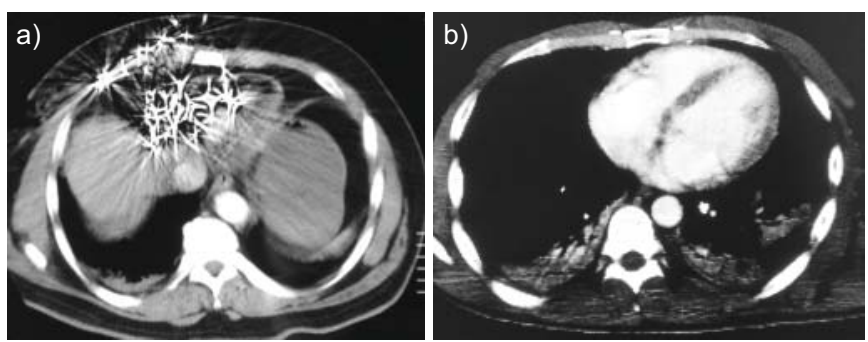

FIGURE 1. Computed tomography images showing a) the classical multiple "star burst" appearance due to multiple shot pellets, and b) evidence of embolisation of multiple shots into the lung.

shotgun fired at close quarters during military duty into the anterior lower thorax. The lower chest wall, liver, pericardium, base of right lung and heart were impregnated with shot pellets, giving the classical multiple "star burst" appearance. (fig. 1a). Extensive debridement of the chest wall wound was performed, with the removal of numerous lead shots. Intracardiac and intrapulmonary shots were left in situ and successfully managed conservatively [5]. He remained asymptomatic. Injuries were monitored by serial CT scans and echocardiograms, which later showed evidence of embolisation of multiple shots into the lung (fig. 1b).
C.S.H. Ng, M.W.T. Kwok and R.H.L. Wong

Dept of Surgery, The Chinese University of Hong Kong, China.

Correspondence: C.S.H. Ng, Dept of Surgery, The Chinese University of Hong Kong, China. E-mail: cshng@netvigator.com

Statement of Interest: None declared

\section{REFERENCES}

1 Jorens PG, Van Marck E, Snoeckx A, et al. Nonthrombotic pulmonary embolism. Eur Respir J 2009; 34: 452-474.

$2 \mathrm{Ng} \mathrm{CSH}$, Lee TW, Yim APC. Iatrogenic causes of hilar radiopaque densities. Eur Respir J 2005; 26: 358.

3 Rickman OB, Utz JP, Aughenbaugh GL, et al. Pulmonary embolization of 2-octyl cyanoacrylate after endoscopic injection therapy for gastric variceal bleeding. Mayo Clin Proc 2004; 79: 1455-1458.

4 Goldman RL, Carmody RF. Foreign body pulmonary embolism originating from a gunshot wound to the head. J Trauma 1984; 24: 277-279.

5 Nagy KK, Massad M, Fildes J, et al. Missile embolization revisited: a rationale for selective management. Am Surg 1994; 60: 975-979.

DOI: 10.1183/09031936.00126709

\section{Impact factor and its role in academic promotion}

\section{To the Editors:}

The following statement was adopted unanimously at the May 17, 2009, meeting of the International Respiratory Journal Editors Roundtable.

In our collective experience as editors of international peerreviewed journals, we propose that the impact factor calculated for individual journals should not be used as a basis for evaluating the significance of an individual scientist's past performance or scientific potential. There are several reasons not to equate the impact factor of a journal in which the scientist publishes with the quality of the scientist's research. For example, as revealed by several recently published analyses of the impact factor [1-6]:

1) A journal's impact factor is determined by a decided minority of its published manuscripts. Thus the impact factor correlates poorly with the citations of an individual manuscript.

2) The impact factor does not consider the number of scientists actively producing research in a given specialty field. Indeed, some journals feel the need to serve constituencies with relatively small numbers of participants who continue to address important questions even though the number of scientists available for citations is limited.

3) A journal's impact factor can be inflated by certain journal practices, such as publication of many review articles.
4) Impact factor measures only the frequency of citations which cannot be assumed to always equate with quality.

There are alternative and we believe more valid measures of the quality and impact of an individual scientist's published contributions. First, a citation record for the individual candidate is readily available via several types of Internet search engines. Second, the time-honoured practice of soliciting evaluations concerning the significance of a candidate's work from scientific peers who are carefully selected to be both highly qualified as well as clearly "arms-length" from the candidate should be rigorously applied.

V. Brusasco*, A.T. Dinh-Xuan*, A.R. Leff ${ }^{\#}$, K.B. Adler ${ }^{\mp}$, R.W. Glenny $^{+}$, J.A. Dempsey ${ }^{+}$, M.L. Levy ${ }^{\S}$, R. Panettieri ${ }^{\dagger}$, H.K. Reddel**, D. Singh $^{\# \#}$ and J.C. Virchow ${ }^{\text {थथ }}$

*European Respiratory Journal, "Proceedings of the American Thoracic Society, "American Journal of Respiratory Cell and Molecular Biology, ${ }^{+}$Journal of Applied Physiology, ${ }^{\S}$ Primary Care Respiratory Journal, ${ }^{f}$ Respiratory Research, **Respirology, \#\#International Journal of COPD, and "Respiratory Medicine.

Correspondence: V. Brusasco, Internal Medicine, University of Genoa, largo R. Benzi 10, Genova, Italy. E-mail: vito.brusasco @unige.it 